\title{
Characterization of waterborne acrylic based paint films and measurement of their water vapor permeabilities
}

\author{
Özge Topçuoğlu, Sacide Alsoy Altinkaya*, Devrim Balköse \\ İzmir Institute of Technology, Department of Chemical Engineering, Gülbahçe Köyü, 35437 Urla-İzmir, Turkey
}

Received 21 December 2005; received in revised form 31 January 2006; accepted 2 February 2006

\begin{abstract}
Recently, production of waterborne coatings has increased significantly as a consequence of strict pollution regulations. Waterborne coatings are sensitive to humidity, thus, their barrier properties with respect to permeation of moisture needs to be determined. Among various coating constituents, binder represents the matrix structure and its amount relative to the amounts of pigments and fillers can significantly affect the structure, hence the barrier property of the coating. In this study, waterborne acrylic based paints applied as protective coating on interior and exterior wall of the buildings are studied. The paint samples formulated with four different binder contents by a commercial paint company are used in the experiments. We first determine unknown ingredients of the paint samples using different characterization tools and then investigate the effect of the binder content on the structure of the paint films. In addition, water vapor permeability of the paint films is measured using a permeation cell. Results show that the barrier property of the waterborne acrylic based paint films against humidity decreases with decreased binder content due to uneven distribution of the pigments, consequently, porous structure formation in the films.
\end{abstract}

(C) 2006 Elsevier B.V. All rights reserved.

Keywords: Waterborne acrylic based paint films; Binder content; Characterization; Water vapor permeation; Barrier property

\section{Introduction}

Recently, waterborne coatings have gained increasing importance due to strict environmental regulations on the emission of volatile organic compounds from solventborne coatings. To maintain constant product quality and to develop new products, structural characterization and measurement of barrier properties of these new coatings become crucial. Waterborne coatings usually contain different additives and an appropriate choice among various alternatives of these additives brings a challenge to both manufacturers and researchers. Several groups have reported the influence of particle morphology, surface treatment of inorganic pigments, corrosion inhibiting additives, fillers, dispersing agents and nature of the binder material on the performance of waterborne coatings [1-7]. Different experimental techniques were used in evaluating the performance and durability of these coatings. Among various techniques, electrochemical methods, especially electrochemical impedance spectroscopy (EIS), have found increasing interest for testing the long

\footnotetext{
* Corresponding author. Tel.: +90 232750 6658; fax: +90 2327506645 .

E-mail address: sacidealsoy@iyte.edu.tr (S.A. Altinkaya).
}

term immersion resistance of the waterborne coatings [2,4-7]. Modern characterization tools such as atomic force microscope (AFM) and scanning acoustic microscope (SAM) combined with scanning electron microscope (SEM) were utilized to determine surface and adhesion properties of the coatings [1,5]. In addition, classical performance measurements such as viscosity, gloss, hazing, creep and pull-off test, rub-out test, salt-spray tests were used to determine rheological, optical, mechanical, adhesion and ageing properties of the coatings [1,3,6-8]. To evaluate the permeability of waterborne coatings, the most commonly used technique is based on a capacitance method in which the change in the coating capacitance is measured as a function of time $[6,7,9,10]$. Perez et al., $[9,10]$ have measured the diffusivity of water in waterborne acrylic, chlorinated rubber and alkyd resin by collecting the capacitance data with the electrochemical impedance spectroscopy. Using the same technique, the diffusivity of water in waterborne epoxy, acrylic-styrene and alkyd based coatings were measured by Galliano and Landolt [6] and Amo et al. [7]. Goossens and his coworkers [11] have utilized an interferometric technique to measure the swelling of a paint film caused by absorption of water vapour. The diffusion coefficient of water in styrene acrylic paint was then determined from the change in the thickness of the paint film. The same research group have 
also used the cup method to measure the diffusion coefficient of water in the waterborne styrene acrylic dispersion wall paint [12]. Delucchi et al. [8] have measured the water vapor permeability of the waterborne epoxy, epoxy+acrylic-polyurethane based coatings using a sorption method.

Review of the literature clearly indicates that there are only few studies on the structural characterization and permeability measurements for the waterborne acrylic based coatings applied on different substrates. Acrylic polymers and copolymers are widely used as a binder in paint formulations due to their good adhesion and film forming properties [13]. In the last decades, they played an important role in cultural heritage conservation as consolidants and/or protectives for wall paintings, statues, stones and porous materials [13]. These two facts motivated us to study the waterborne acrylic based paints, which are applied as protective coatings on interior and exterior wall of the buildings. The protective coatings used, as indoor/outdoor wall paints should fulfill different requirements such as improved mechanical, optical, rheological, adhesion, ageing properties and reduced water absorption and water vapor permeability. In the case of waterborne protective coatings, water vapor permeability is considered to be the most important performance criteria, since these coatings are directly exposed to rain and high humidity levels both in indoor and outdoor environment and they are highly sensitive to humidity. Water diffusion into the wall paint leads to growth of microorganisms and loss of adhesion between the coating and substrate. In addition, water is the main carrier for the penetration of aggressive ions originating from rain and water soluble gases such as $\mathrm{CO}_{2}$ and $\mathrm{SO}_{2}$ which both cause a negative effect on the protection of concrete. Thus, measurement of the water vapor permeability is necessary for evaluating the effectiveness of the waterborne wall paints in concrete protection.

The major purpose of this work is to investigate the effect of binder content on the structure and the water vapor permeability of the waterborne acrylic based paints applied on the interior and exterior wall of the buildings. To achieve this goal, the structure of the paint films are observed from scanning electron microscope images and the water vapor permeabilities are measured using a permeation cell. In addition, the main ingredients of the paint samples are determined using different characterization tools since the paint formulation is not provided by the commercial paint company which supplied the samples. The results are used to demonstrate the relationship among the amount of binder used in the formulation, the resulting morphology and the water vapor permeability of the paint films.

\section{Theory and principles}

In typical water permeation experiments two sides of the films are exposed to different activity of the penetrant. If it is assumed that transport in the film is one dimensional and takes place only by Fickian diffusion, then the flux of the permeant, J, is described as follows:

$J=-D_{\text {eff }} \frac{\partial C}{\partial x}$ where $D_{\text {eff }}$ and $C$ are the effectivity diffusivity and the concentration of the permeant in the film, respectively. Furthermore, it is assumed that the thickness of the film, $L$, is so thin that steadystate condition is quickly achieved in the film even though the concentrations of the permeant at both sides of the film may change with time. If it is considered that diffusion coefficient is independent of concentration, then, Eq. (1) can be integrated from $x=0$ to $L$ to find the following expression for the flux.

$J=\frac{D_{\text {eff }}}{L}\left(C_{1 \mathrm{~L}}-C_{1 \mathrm{U}}\right)$

Where $C_{1 \mathrm{~L}}$ and $C_{1 \mathrm{U}}$ are the concentration of the permeant at both sides of the film. If a linear equilibrium relationship between the concentrations of the permeant in the vapor and the film is assumed,

$C_{1 \mathrm{~L}}=P_{1 \mathrm{~L}} S_{\mathrm{eff}}$

$C_{1 \mathrm{U}}=P_{1 \mathrm{U}} S_{\mathrm{eff}}$

then, the flux of the permeant is given as follows:

$J=\frac{D_{\text {eff }} S_{\text {eff }}}{L}\left(P_{1 \mathrm{~L}}-P_{1 \mathrm{U}}\right)$

In Eq. (3)-(5), $P_{1 \mathrm{~L}}$ and $P_{1 \mathrm{U}}$ denote partial pressure of the permeant in the vapor phases surrounding the both sides of the film. The product $D_{\text {eff }} S_{\text {eff }}$ in Eq. (5) is called as permeability coefficient, $P_{\text {eff }}$ and $S_{\text {eff }}$ is the effective solubility of the permeant in the film. Molecules permeating through the film cause an increase in partial pressure of the permeant in the upper volume of the cell. If vapor phase is assumed to be ideal, then an increase in pressure of the permeant is given by the following expression;

$\frac{V_{\mathrm{u}}}{R T} \frac{\mathrm{d} P_{1 \mathrm{U}}}{\mathrm{d} t}=J A$

Where $V_{\mathrm{u}}$ is the volume of the upper cell, $A$ is the area of the membrane and $T$ is the temperature in the upper compartment. If Eqs. (5) and (6) are combined;

$\frac{\mathrm{d} P_{1 U}}{\mathrm{~d} t}=\frac{R T}{L} \frac{A}{V_{\mathrm{u}}} P_{\mathrm{eff}}\left(P_{1 \mathrm{~L}}-P_{1 \mathrm{U}}\right)$

and if partial pressure of the permeant in the lower compartment is maintained constant, then Eq. (7) can be integrated between the limits;

$t=0 \quad P_{1 \mathrm{U}}=P_{1 \mathrm{U} i}$

$t=t \quad P_{1 \mathrm{U}}=P_{1 \mathrm{U}(t)}$

to give the following expression;

$\ln \frac{P_{1 \mathrm{~L}}-P_{1 \mathrm{U} i}}{P_{1 \mathrm{~L}}-P_{1 \mathrm{U}(t)}}=\frac{P_{\mathrm{eff}} A R T}{V_{\mathrm{u}} L} t$

Permeability coefficient, $P_{\text {eff }}$, can be calculated from the slope of $\ln \left(P_{1 \mathrm{~L}}-P_{1 \mathrm{U} i}\right) /\left(P_{1 \mathrm{~L}}-P_{1 \mathrm{U}(t)}\right)$ versus time graph. 


\section{Materials and methods}

\subsection{Materials}

Waterborne acrylic based paints containing different binder contents $(40 \%, 30 \%, 20 \%$ and $10 \%)$ were prepared and supplied by Akril Kimya A.S. Methylmethacrylate-co-butylacrylate copolymer was used as a binder in the formulation. The binder was produced and supplied by Organik Kimya A.S. in the form of an emulsion consisting of 50\% copolymer and 50\% water by volume. The paint used in this study is applied both on the interior and exterior wall of the buildings.

\subsection{Solid-liquid ratio analysis of the paint samples}

The solid-liquid ratio of the liquid paint samples was determined by using Sartorius Moisture Analyzer (Model number: MA 100, resolution: $0.1 \mathrm{mg}$ ). The liquid samples were cast onto aluminium pans and the initial weight of the samples and the tares of the pans were measured. Standard drying was selected as heating program and the temperature was set to $70^{\circ} \mathrm{C}$. Until the temperature reach the set value, an empty pan was placed into the device. While changing the pans, the maximum temperature deviation caused by opening the lid was $277 \mathrm{~K} / \mathrm{min}$. Thus, it could be said that the drying kinetic of the samples was studied under constant temperature. After $2 \mathrm{~h}$ of drying in the moisture analyzer, the samples were placed into a vacuum oven maintained at $80^{\circ} \mathrm{C}$. The drying process in the vacuum oven continued for 2 weeks until no change in weight of the samples was observed.

\subsection{Film preparation method}

Paint and pure copolymer films were prepared by casting the solution on a clean and smooth glass substrate through an automatic film applicator (Sheen Instruments Ltd., model number $1133 \mathrm{~N})$. The thickness of the cast films were adjusted by a four sided applicator with the gap sizes ranging from 30 to $300 \mu \mathrm{m}$. Most of the water in the film was removed over the course of an hour in a vacuum oven maintained at $100^{\circ} \mathrm{C}$. The films were easily removed from the glass substrate by immersing the samples in a water bath for a certain period of time ranging from $30 \mathrm{~s}$ to $37 \mathrm{~min}$. To remove residual water, the films were redried in the vacuum oven for 3 days at a temperature of $100^{\circ} \mathrm{C}$.

\subsection{Characterization studies of paint films}

No information about the paint ingredients was provided by the supplier except the type and amount of the binder material used in the formulation. Thus, as discussed below, we have used different characterization tools to identify the main ingredients of the paint as well as to observe the structure of the paint films.

\subsubsection{Scanning electron microscope}

The structure of the paint films from their air-contacting and glass-contacting surfaces was determined using scanning electron microscope (Philips XL 30 S FEG) secondary electron imaging (SEI) detector. In addition, cross sectional micrographs were taken to measure average thickness of the paint films using the SEI detector.

\subsubsection{Energy dispersive $X$-ray (EDX)}

EDX analysis was carried out on the opaque surfaces to determine the elements in the paint films. Data were collected from 20 randomly chosen points and by taking arithmetic mean of these values; average weight percent of the elements was calculated.

\subsubsection{Fourier transform infrared spectroscopy (FT-IR)}

FT-IR spectrophotometer (Shimadzu 8601 PC) was used to obtain information about functional groups in the paint films. The resolution was $4 \mathrm{~cm}^{-1}$. The range of the wavenumber was between 400 and $4600 \mathrm{~cm}^{-1}$. Sensitive pyroelectric type of DLATGS (deuterium triglyceride sulfide which is adapted by L-alanine) element was mounted on the FT-IR-8601 PC as a detector and transmission spectra of the films were recorded.

\subsubsection{Thermal gravimetry (TGA)}

Thermal gravimetric analysis was carried out to observe changes in thermal events in the paint films using Shimadzu TGA-51. The paint films were heated from 25 to $1000^{\circ} \mathrm{C}$ while the pure copolymer sample was heated up to $600{ }^{\circ} \mathrm{C}$ at a rate of $283 \mathrm{~K} / \mathrm{min}$ under $30 \mathrm{~cm}^{3} / \mathrm{min}$ and $40 \mathrm{~cm}^{3} / \mathrm{min}$ nitrogen flow.

\subsubsection{Differential scanning calorimetry (DSC)}

Differential scanning calorimetry (Shimadzu DSC-50) was used to determine the glass transition temperatures of the paint films. Samples were heated up to $500{ }^{\circ} \mathrm{C}$ at a heating rate of $274 \mathrm{~K} / \mathrm{min}$ until $30^{\circ} \mathrm{C}$ and $278 \mathrm{~K} / \mathrm{min}$ above $30^{\circ} \mathrm{C}$ under nitrogen as a purge gas with a flowrate of $40 \mathrm{~cm}^{3} / \mathrm{min}$.

\subsection{6. $X$-ray diffraction $(X R D)$}

Philips $X^{\prime}$ Pert Pro diffractometer was used to investigate the crystalline form of the elements present in the paint films. The operating conditions were $45 \mathrm{kV}$ and $45 \mathrm{~mA}$. $\mathrm{Cu} \mathrm{K} \alpha$ radiation, $\lambda=0.15406 \AA$, was carried out. The range for the X-ray scan was made over $2 \theta$ values of $5^{\circ}-70^{\circ}$ with a scan speed of $0.06^{\circ} \%$. The data were collected with $X^{\prime}$ Pert data collector and $X^{\prime}$ Pert Graphics \& Identify software was used to record the XRD intensities. The crystalline peaks were identified by matching with standard reference patterns from PCDFW in database maintained by the International Centre for Diffraction Data (ICDD).

\subsection{Permeability studies}

Permeability studies were performed in a vessel consisting of three separable parts as shown in Fig. 1. The bottom part contains a small bath filled with deionized water. The middle part with an inner diameter of $5.8 \mathrm{~cm}$ consists of a hole to fix the films. The films sealed between two O-rings with vacuum grease were placed between upper and lower part of the cell. In order to prevent contamination and any possible leakage, the rings were renewed for almost each experiment and the films were cut in such a manner that their diameters are greater than that of the hole. The upper part of the permeation set-up includes 


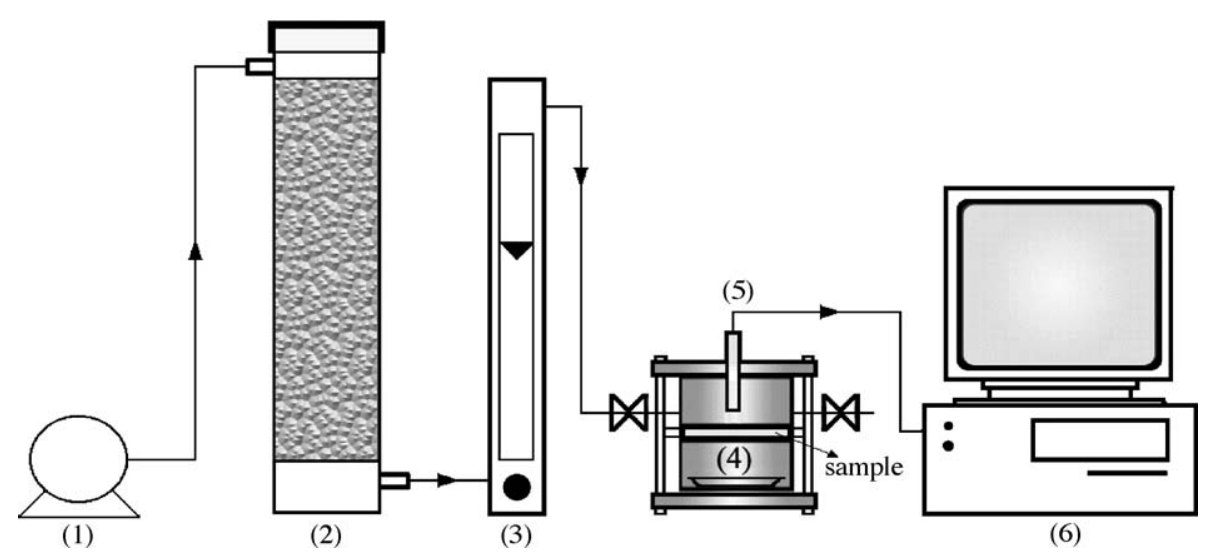

Fig. 1. Schematic diagram of the permeation set-up. (1) Pump; (2) fixed bed column; (3) flowmeter; (4) deionized water bath; (5) humidity sensor; (6) computer.

a humidity probe connected to a Datalogger SK-L $200 \mathrm{TH}$ to monitor and record humidity and temperature versus time data.

During typical permeation experiments, air was dried in a fixed bed Drierite column that contains anhydrous $\mathrm{CaSO}_{4}$ and molecular sieve $5 \mathrm{~A}$ as adsorbents and then continuously pumped through the upper part of the permeation cell at a flowrate of $610 \mathrm{~cm}^{3} / \mathrm{min}$ for a period of at least $6 \mathrm{~h}$. When the relative humidity in the upper part of the cell was lowered to 5\%, valves at the inlet and outlet of the permeation cell were closed, the program was started and the temperature and relative humidity data were recorded with $10 \mathrm{~s}$ interval. Before the experiments, it was ensured that the system does not have any leakage. For this purpose, the water bath was removed and no film was placed between the compartments. The upper part of the set-up was flushed with dry air for at least $6 \mathrm{~h}$ until relative humidity was lowered to $5 \%$. After the valves were closed, no change in the relative humidity was observed for a long period of time. Results are reported as an average of two measurements.

\section{Results and discussion}

\subsection{Solid-liquid ratio analysis of the paint samples}

Water based paints are dispersion of pigments, fillers and binders in water. Dispersion agents, thickeners and antifoam agents are added to obtain a stable dispersion. When the paint is spread on a solid surface, water evaporates and a paint film is obtained. Thus, water content of the paints is an important parameter affecting the properties of the paints. Table 1 summarizes the decrease in weight of the paint samples due to evaporation of water after each drying process $\left(\right.$ at $70^{\circ} \mathrm{C}$ and $80^{\circ} \mathrm{C}$ in vacuum). It was observed that the paint samples for- mulated with $20 \%$ and $10 \%$ binder, loose most of their water content in the first drying process at $70^{\circ} \mathrm{C}$, while their weight losses in the second step at $80^{\circ} \mathrm{C}$ are small compared to those of the other samples. All paint samples contained nearly the same amount of water around $35 \%$.

\subsection{Characterization of the paint films}

\subsubsection{Surface micrographs of the paint films}

When detached from the glass substrate, the lower surfaces of all paint films facing to the glass substrate were found to be smooth and glossy while the free surfaces in contact with air during drying were highly rough and opaque. The scanning electron microscope pictures of these films taken over the cross section are shown Fig. 2a-d. The micrographs in these figures indicate that a decrease in binder content from $40 \%$ to $10 \%$ results in the formation of more porous structures. Porous structure formation in the paint films is a result of the pigment flocculation due to insufficient wetting of the pigments by the binder. As shown in Fig. 3a-d, surface micrographs taken at higher magnification from opaque sides of the films allow to observe the distribution of the pigments. In the case of $40 \%$ binder, pigments and fillers exhibit a relatively homogeneous distribution (see Fig. 3a). However, pigment distribution becomes nonhomogeneous especially in the paint films formulated with $20 \%$ and $10 \%$ binder.

\subsubsection{Elemental composition of the paint films}

Average weight percent of the elements present in the paint films are represented in Table 2. According to the EDX analysis, the common elements found in each film are carbon, oxygen, titanium, calcium, silica, aluminium, magnesium, and sodium.

Table 1

Weight loss of the paint samples after the first and second drying processes

\begin{tabular}{lllll}
\hline Sample & $\begin{array}{l}\text { Weight loss at } \\
70{ }^{\circ} \mathrm{C}(\%)\end{array}$ & $\begin{array}{l}\text { Weight loss at } 80^{\circ} \mathrm{C} \\
\text { under vacuum }(\%)\end{array}$ & $\begin{array}{l}\text { Total weight } \\
\text { loss }(\%)\end{array}$ & $\begin{array}{l}\text { Remaining solid at the end of } \\
\text { the drying processes }(\%)\end{array}$ \\
\hline $40 \%$ Binder & 20.0 & 14.0 & 34.0 & 65.9 \\
$30 \%$ Binder & 22.3 & 11.3 & 33.6 & 66.4 \\
$20 \%$ Binder & 28.7 & 3.7 & 32.4 & 67.6 \\
$10 \%$ Binder & 27.8 & 3.8 & 31.6 & 68.4 \\
\hline
\end{tabular}


(a)

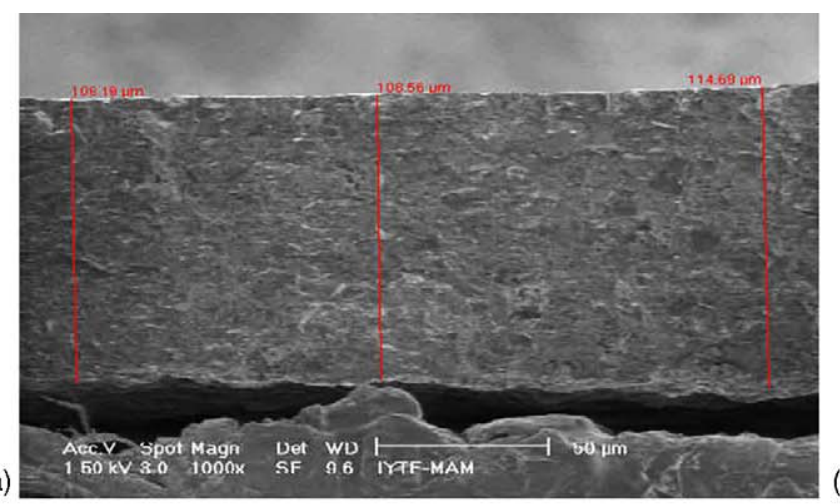

(c)

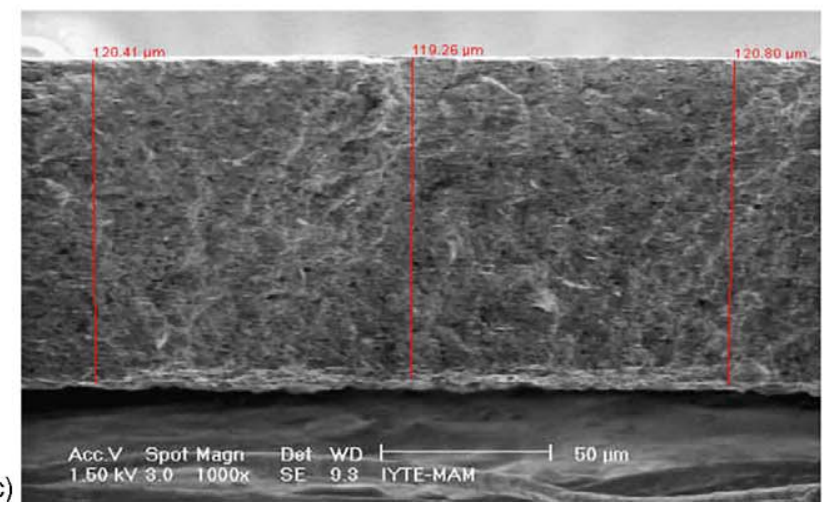

(b)
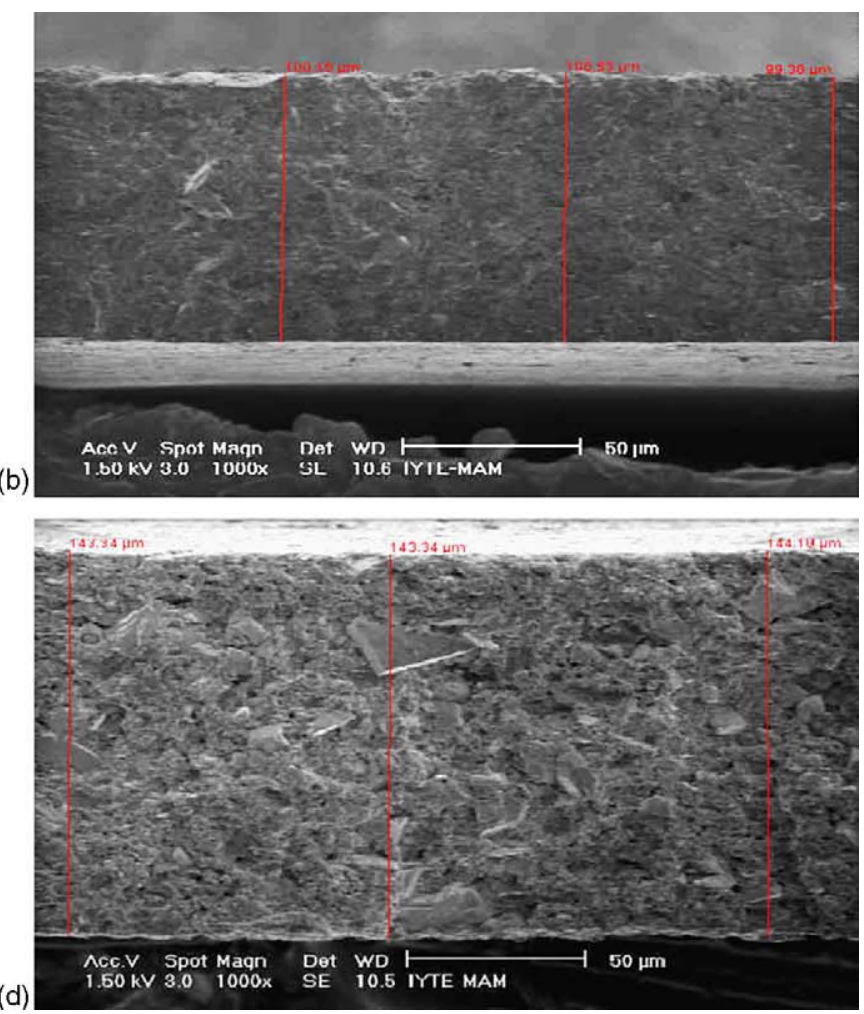

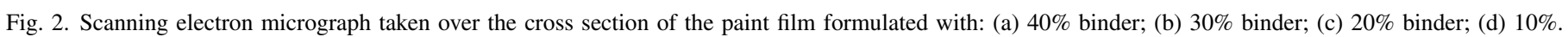
Magnification, $1000 \times$.

The average amount of carbon element decreases from 50.3\% to $26.9 \%$ as the binder percentage decreases from $40 \%$ to $10 \%$, however, oxygen amount remains nearly the same. As will be shown below in X-ray analysis results, all elements except oxygen and carbon are found as oxygen containing compounds in the paint, while carbon is only seen in calcite besides the binder material. Since these oxygen containing elements are found in a significant amount in the paint formulated with $10 \%$ binder, it is not surprising to see relatively high amount of oxygen and low amount of carbon in this paint. As expected, weight percentages of $\mathrm{Ca}$ and $\mathrm{Si}$ elements increase with decreased binder content. $\mathrm{Al}$ and $\mathrm{Si}$ elements present in the paint could be in the form of aluminum silicate, in addition, Si element could exist as silica, which is used as a thickener.

\subsubsection{Functional groups in the paint films}

Fig. 4a-d show that FT-IR spectra of the paint films include many common peaks expected from the binder, pigment and filler in the paint. The peaks observed at around $2960 \mathrm{~cm}^{-1}$ are due to $\mathrm{C}-\mathrm{H}$ streching bands, while the peaks around 1720

Table 2

Average weight percent of elements present in the paint films

\begin{tabular}{llllllllr}
\hline Binder $(\%)$ & $\mathrm{C}$ & $\mathrm{O}$ & $\mathrm{Na}$ & $\mathrm{Mg}$ & $\mathrm{Al}$ & $\mathrm{Si}$ & $\mathrm{Ca}$ & $\mathrm{Ti}$ \\
\hline 40 & 50.3 & 37.4 & 0.7 & 0.9 & 1 & 3.2 & 2.7 & 3.8 \\
30 & 45.2 & 40.9 & 0.8 & 1 & 1.1 & 3.8 & 3.4 & 3.8 \\
20 & 41.6 & 42.3 & 0.7 & 1.1 & 1 & 3.3 & 4.3 & 5.7 \\
10 & 26.9 & 42.2 & 0.9 & 1.3 & 1.5 & 5.2 & 9.4 & 12.5 \\
\hline
\end{tabular}

and $1175 \mathrm{~cm}^{-1}$ correspond to $\mathrm{C}=\mathrm{O}$, and $\mathrm{C}-\mathrm{O}$ (ester bound) streching vibrations, respectively. These peaks are all indicative of an acrylic [poly(methylmethacrylate/ $n$-butyl acrylate)] based binder material.

The absorption peaks at around 1797, 1420, 870 and $720 \mathrm{~cm}^{-1}$ are characteristic of calcium carbonate, which is commonly used as a filler in paint formulation. Reigh et al. [14] have reported that calcite, which is one of the most commonly seen form of the calcium carbonate, has peaks at 1420, 875 and $712 \mathrm{~cm}^{-1}$. Sönmez and Cebeci [15] have indicated that IR bands at 854.4 and $875.6 \mathrm{~cm}^{-1}$ are characteristics of the carbonate in calcite. The peaks observed in our samples between $3610-3640 \mathrm{~cm}^{-1}, 1120-1140 \mathrm{~cm}^{-1}$, and $900-1050 \mathrm{~cm}^{-1}$ show the presence of hydrated aluminium silicate which is also used as a filler in the paint formulation. Reigh et al., [14] analyzed quartz samples which is one of the minerological forms of the silica. In their study, the peaks at 798 and $779 \mathrm{~cm}^{-1}$ were attributed to silica. According to Colthup et al. [16] silica absorbs near $1100 \mathrm{~cm}^{-1}$. In our samples, the peaks observed between 1090 and $1110 \mathrm{~cm}^{-1}$ support the presence of silica.

For all samples we have studied, the absorption peaks between 700 and $500 \mathrm{~cm}^{-1}$ are characteristic of $\mathrm{TiO}_{2}$ since the strongest band range belonging to $\mathrm{TiO}_{2}$ was denoted in the region of $700-500 \mathrm{~cm}^{-1}$ by Colthup et al. [16]. In the study of Vitala et al. [17] the bands between 600 and $450 \mathrm{~cm}^{-1}$ was attributed to the amorphous $\mathrm{TiO}_{2}$. Burgos and Langlet [18] studied $\mathrm{TiO}_{2}$ sol-gel reactions and in IR studies they found bands belonging to $\mathrm{Ti}-\mathrm{O}$ and $\mathrm{Ti}-\mathrm{O}-\mathrm{Ti}$ groups in the range of $800-400 \mathrm{~cm}^{-1}$. 
(a)
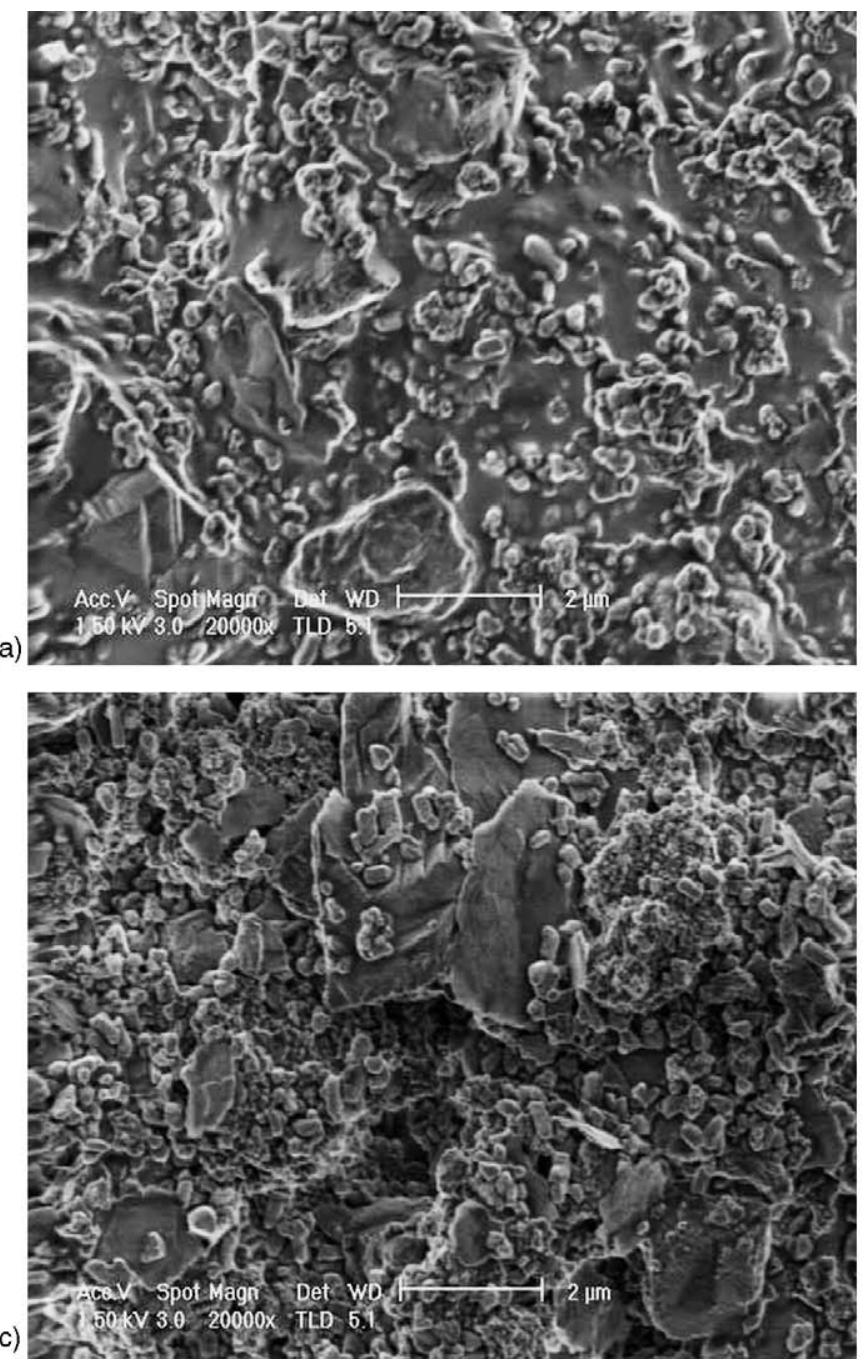
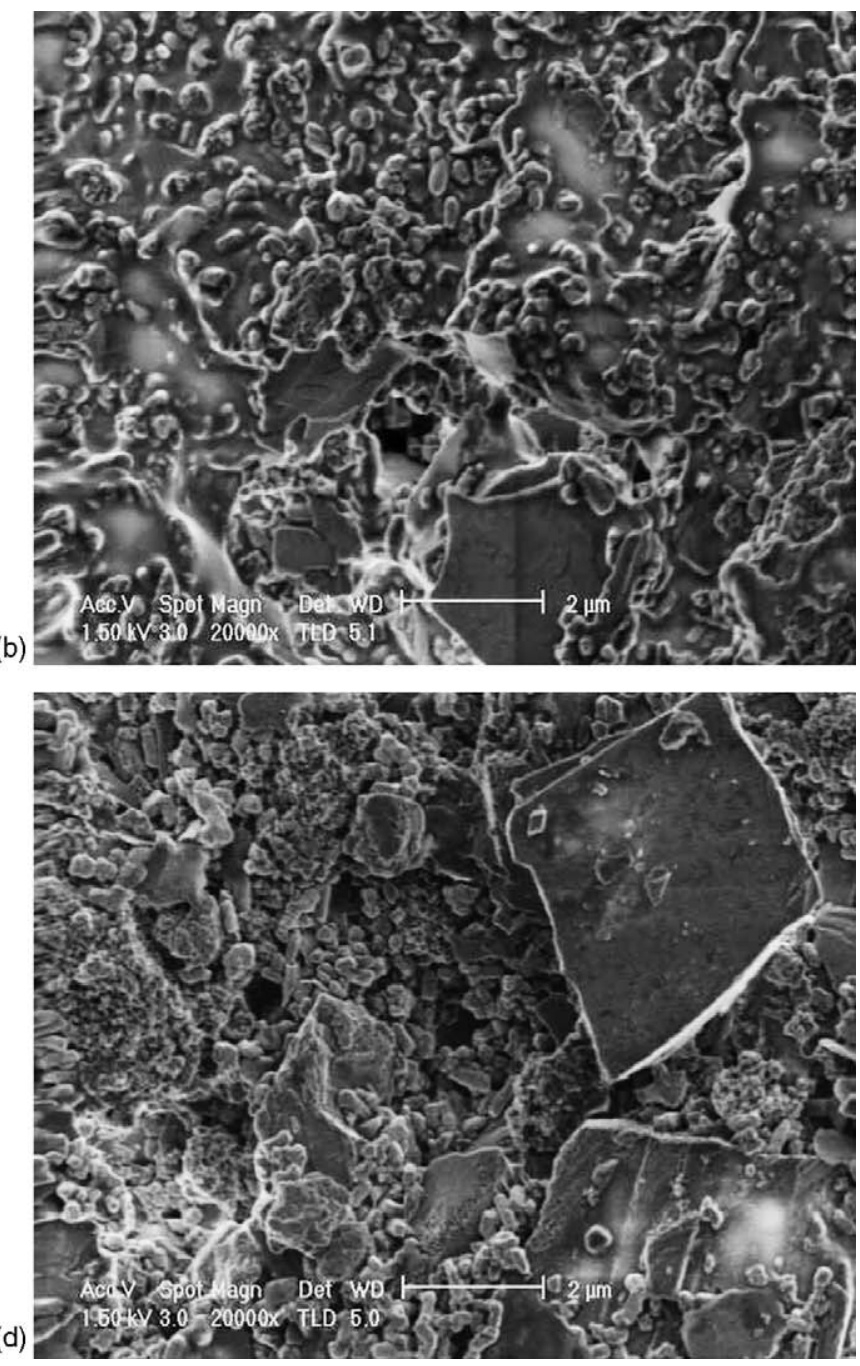

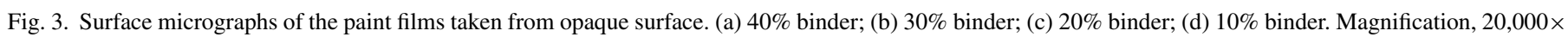

\subsubsection{Thermal analysis of the paint films}

Figs. 5 and 6 show the TGA curves of the paint films and pure copolymer film, respectively. The films did not contain any water since no mass loss occurs up to $260^{\circ} \mathrm{C}$. According to these results, degradation process of the paint films occurs at two steps (around $260^{\circ} \mathrm{C}$ and $660^{\circ} \mathrm{C}$ ), whereas the thermal degradation of the pure copolymer film takes place at one step (around $260^{\circ} \mathrm{C}$ ). Pure copolymer film looses all of its weight, however, the paint films leave a thermally stable char at $1000^{\circ} \mathrm{C}$. The degradation temperatures of the films and weight losses are summarized in Table 3. It is seen that if the binder amount in the paint decreases, the total weight loss of the paint also decreases.

Weight loss in the first step is mainly associated with the decomposition of the binder material, methylmethacrylate-cobutylacrylate copolymer, since weight losses decrease and the temperature range of the degradation process becomes narrow with decreased binder content. Weight loss in the second step around $660^{\circ} \mathrm{C}$ is attributed to the degradation of calcite into calciumoxide and carbondioxide by the following reaction:

$\mathrm{CaCO}_{3}(\mathrm{~s}) \rightarrow \mathrm{CaO}(\mathrm{s})+\mathrm{CO}_{2}(\mathrm{~g})$
In the second step, all the samples had nearly the same amount of weight loss around $25 \%$ indicating that they were formulated with the same $\%$ of $\mathrm{CaCO}_{3}$. At the end of the second step weight loss, the residual thermally stable char contains $\mathrm{CaO}$ and titania which are both stable over $1000{ }^{\circ} \mathrm{C}$.

\subsubsection{Differential scanning calorimetric analysis of the paint films}

Figs. 7 and 8 show the DSC curves of the paint and pure copolymer films obtained in nitrogen athmosphere, respectively. The glass transition temperatures of the paint films were determined as $34.14,34.11,32.82$ and $33.96^{\circ} \mathrm{C}$ while the glass transition temperature of the pure copolymer was found as $31.67^{\circ} \mathrm{C}$. These results suggest that addition of pigments, fillers and other additives does not significantly influence the glass transition temperature of the paint films. This situation may be caused due to the weak interaction between the pigments and the acrylic binder [19].

Paint films exhibit two exothermic decomposition peaks while the pure copolymer gives a single endothermic decomposition peak as seen in Figs. 7 and 8. During the decomposition 


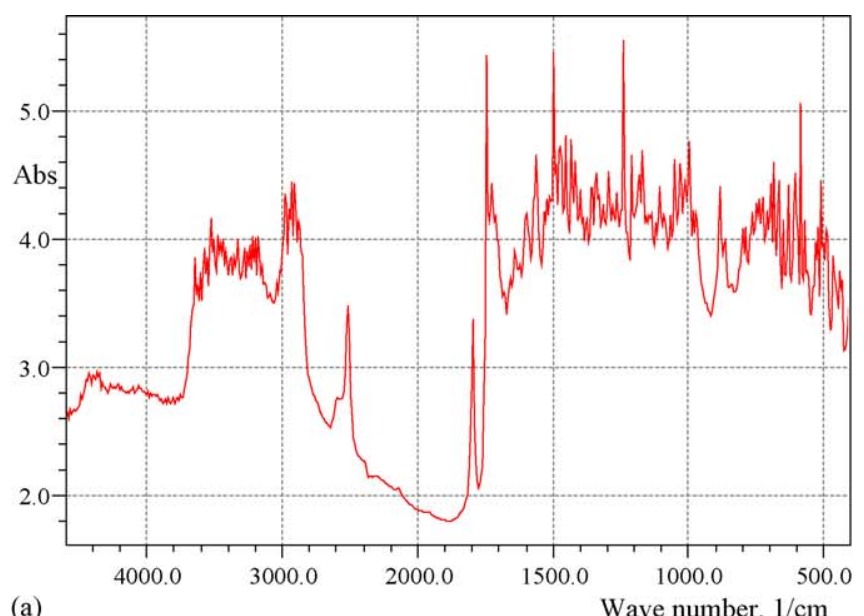

(a)

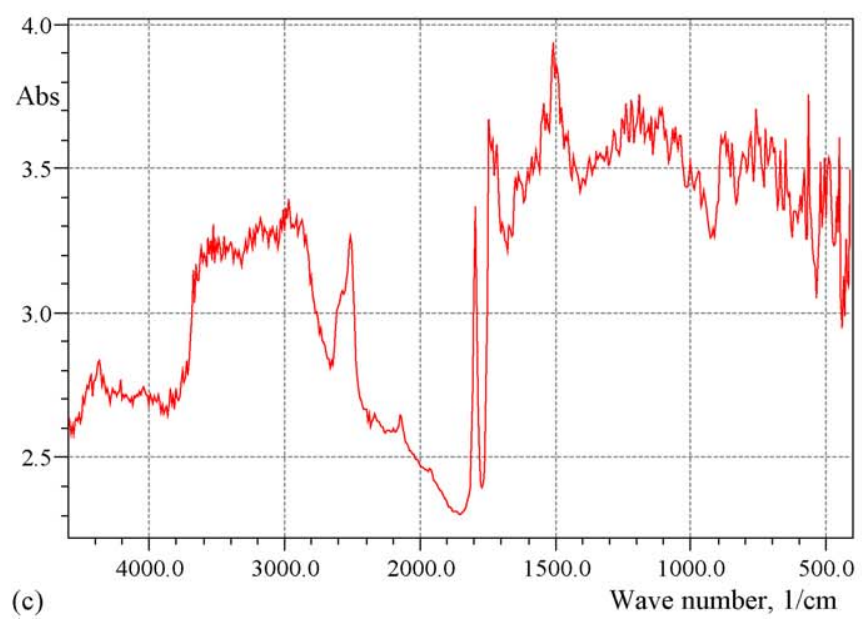

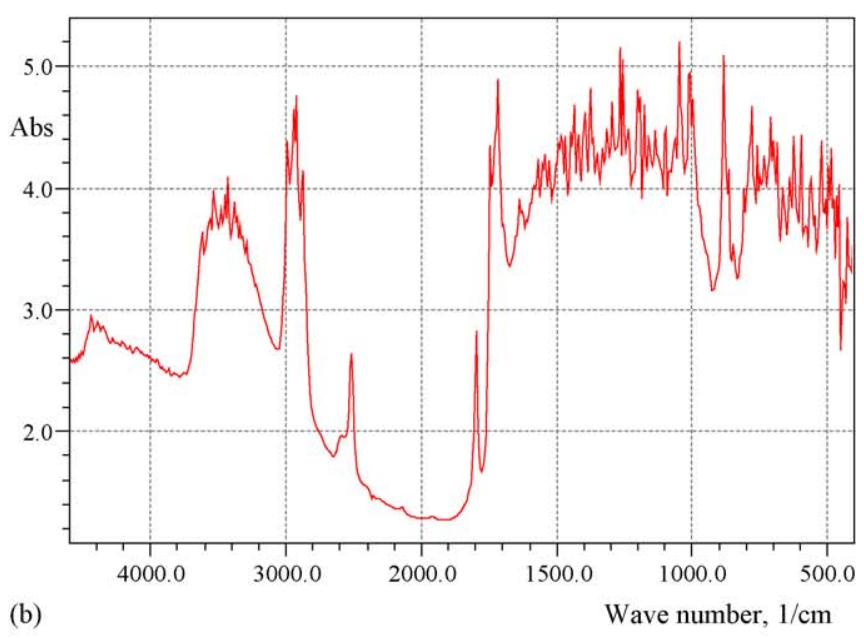

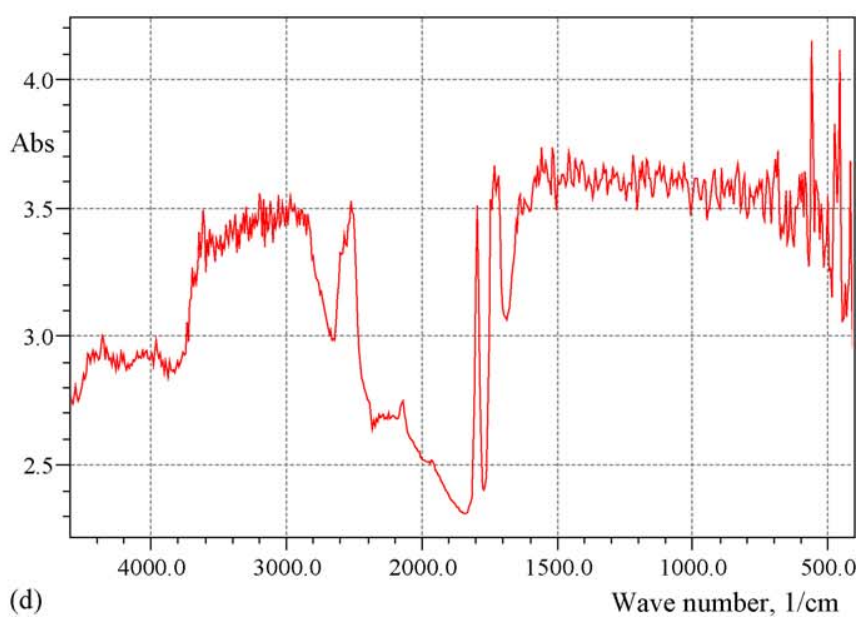

Fig. 4. FT-IR spectra of the paint films: (a) $40 \%$ binder; (b) $30 \%$ binder; (c) $20 \%$ binder; (d) $10 \%$ binder.

of the paint films, heat is released due to thermal degradation of the binder, reactions between the binder and pyrolysis products of binder and the fillers. In literature, formation of metallic soaps in alkyd paints formulated with metal oxide pigments have been reported. For example zinc oxide and lead oxide fillers react with ester groups of alkyds and form zinc soaps and lead soaps [19]. However, in the case of pure copolymer degradation, only endothermic thermal degradation reactions occur. When the TGA curves in Figs. 5 and 6 and DSC curves in Figs. 7 and 8 are compared, it is clearly seen that the exothermic peaks in DSC curves are related to mass loss from the paint films with formation of volatile thermal degradation products. The reaction of the acrylates with inorganic oxides in the films could also be exothermic reactions. Pagella and De Faveri [20] reported that the binder content of the latex paints could be estimated by differential scanning calorimetry. They have found overall heat output to be proportional to the amount of polymer even if the decomposition paths are very different for the same polymer at different concentrations. To determine the total enthalpy of all probable reactions in the present study, the area under the whole exotherm was integrated and the results are summarized in Table 4. Experimental data for the four different paint films were then gathered in Fig. 9, plotting measured $\Delta H(\mathrm{~kJ} / \mathrm{kg})$ versus \% binder content. The results show a good linear relation between heat output and polymer concentration. Thus, it appears that determination of heat output from thermal decomposition

Table 3

Degradation temperature and weight loss of the paint films

\begin{tabular}{llllllll}
\hline Sample & $\begin{array}{l}\text { Total weight } \\
\text { loss }(\%)\end{array}$ & $\begin{array}{l}\text { First step } \\
\text { weight loss }(\%)\end{array}$ & $\begin{array}{l}\text { Second step } \\
\text { weight loss }(\%)\end{array}$ & $\begin{array}{l}T_{\text {onset }} \text { of first } \\
\text { step }\left({ }^{\circ} \mathrm{C}\right)\end{array}$ & $\begin{array}{l}T_{\text {endset }} \text { of first } \\
\text { step }\left({ }^{\circ} \mathrm{C}\right)\end{array}$ & $\begin{array}{l}T_{\text {onset }} \text { of second } \\
\text { step }\left({ }^{\circ} \mathrm{C}\right)\end{array}$ & $\begin{array}{l}T_{\text {endset }} \text { of second } \\
\text { step }\left({ }^{\circ} \mathrm{C}\right)\end{array}$ \\
\hline $40 \%$ Binder & 47.51 & 26.36 & 24.49 & 257.4 & 411 & 667.1 & 776.2 \\
$30 \%$ Binder & 43.67 & 21.22 & 24.24 & 258.3 & 409.2 & 668.9 \\
20\% Binder & 39.82 & 15.38 & 24.94 & 269.4 & 400.3 & 663.8 \\
10\% Binder & 34.88 & 9.21 & 24.89 & 276.2 & 400.1 & 661.7 & 776.3 \\
Pure Binder & 99.18 & 99.18 & - & 263.6 & 599.9 & - \\
\hline
\end{tabular}




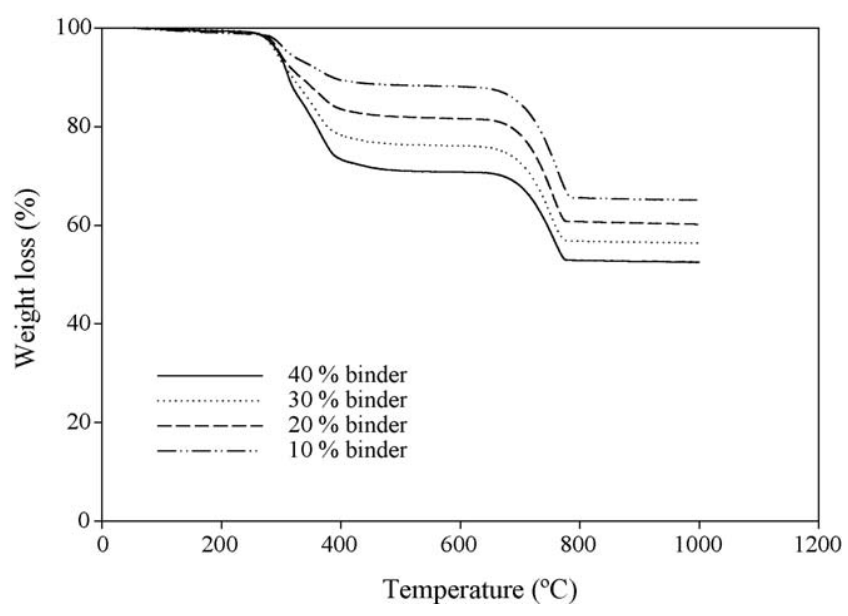

Fig. 5. TGA curves of the paint films.

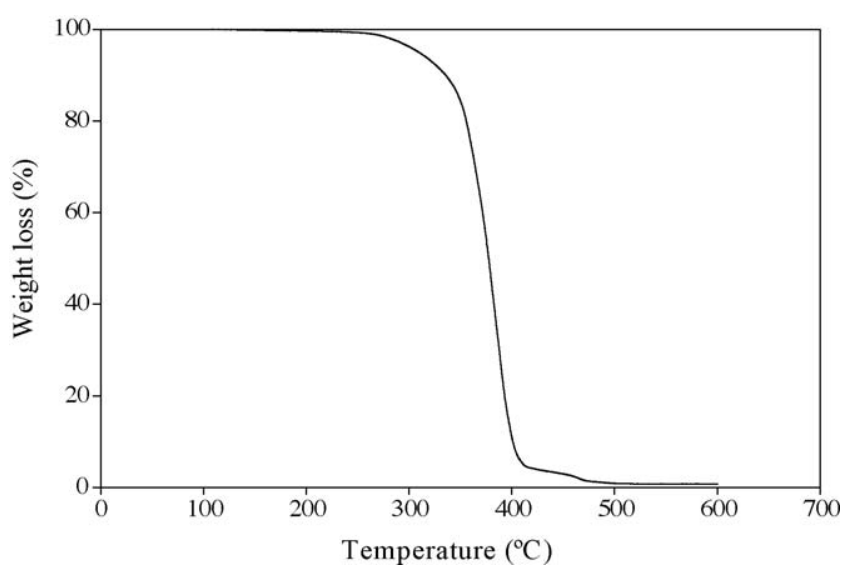

Fig. 6. TGA curve of the pure binder material.

of organic fraction in the paint by using DSC in nitrogen atmosphere may be utilized to estimate the binder concentration in the paint films. Similar result was reported by Pagella and De Faveri [20] who also showed a linear relation between heat out put in DSC analysis in air and the binder content of the paint films.

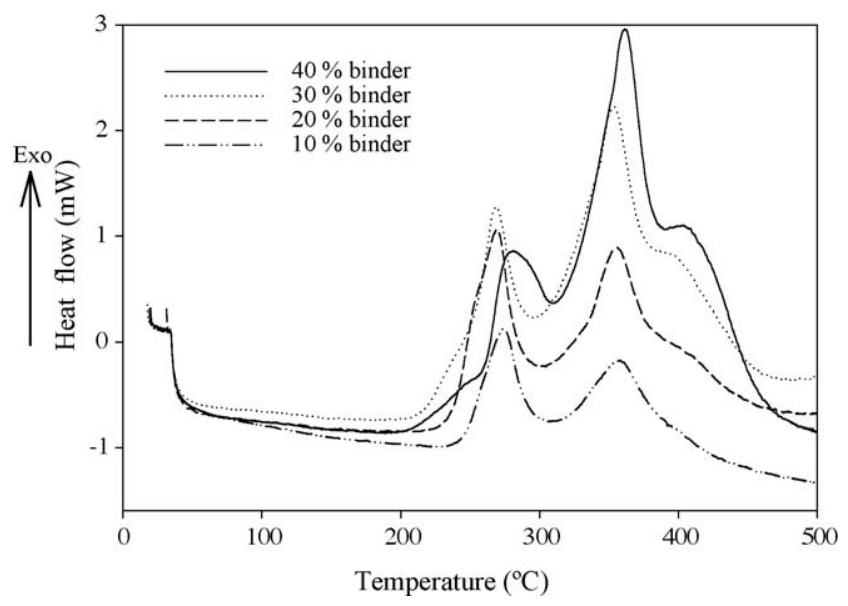

Fig. 7. DSC curves of the paint films.

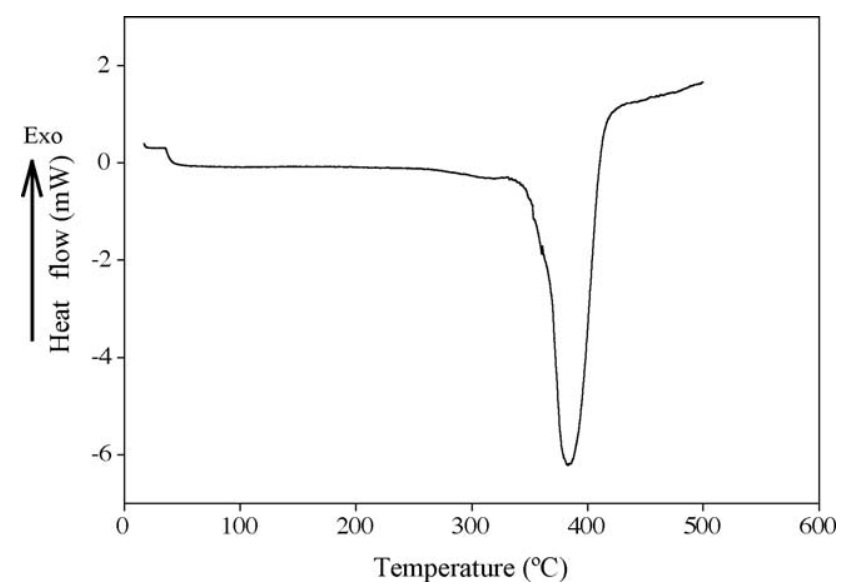

Fig. 8. DSC curve of the pure binder material.

Table 4

Exothermic decomposition peak temperatures, heat of decomposition of the binder in the films and permeability coefficients of water vapour through pure copolymer and paint films

\begin{tabular}{lcccc}
\hline Sample & $T_{\text {onset }}\left({ }^{\circ} \mathrm{C}\right)$ & $T_{\text {endset }}\left({ }^{\circ} \mathrm{C}\right)$ & $\Delta H(\mathrm{~kJ} / \mathrm{kg})$ & $\begin{array}{l}P_{\text {eff }} \times 10^{12} \\
(\mathrm{~mol} / \mathrm{s} \mathrm{cm} \mathrm{kPa})\end{array}$ \\
\hline $100 \%$ Binder & - & - & - & 0.73 \\
$40 \%$ Binder & 214.1 & 498.5 & 364.5 & 0.78 \\
$30 \%$ Binder & 220.1 & 477.8 & 271.4 & 1.69 \\
$20 \%$ Binder & 226.8 & 494.1 & 182.9 & 13.65 \\
$10 \%$ Binder & 233.3 & 499.9 & 107 & 26.97 \\
\hline
\end{tabular}

\subsubsection{Crystalline structures of the paint films}

According to the X-ray diffraction analysis, all paint films give nearly the same diagrams as shown in Fig. 10. From the analyis it was found that, calcium is in the form of calcite $\left(\mathrm{CaCO}_{3}\right)$ as expected. The crystalline peaks of this compound are observed at ${ }^{\circ} 2 \theta=23.2,29.5,31.5,36,39.5,43.2,47.2,47.5,48.5,56.5$, 57.5, 58.2, 60.8, 61, 61.5, 63.1, 64.8, 65.6, 69.2 [21]. Titanium is in the form of titania $\left(\mathrm{TiO}_{2}\right)$ and gives peaks at the ${ }^{\circ} 2 \theta$ angles of $27.5,36,39.3,41.3,44.2,54.5,56.7,62.8,64.1,65.7,69.1$, 69.8 .

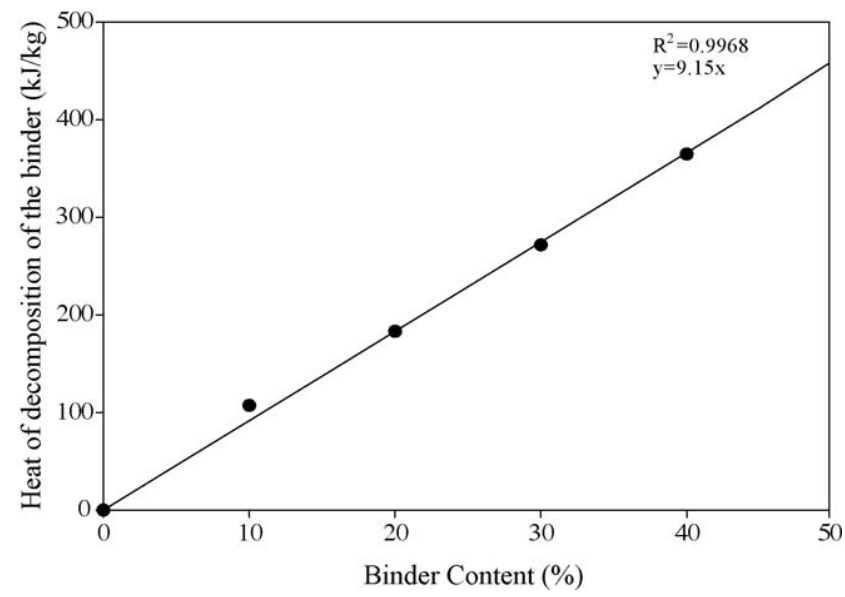

Fig. 9. Heat of decomposition as a function of the binder content. 


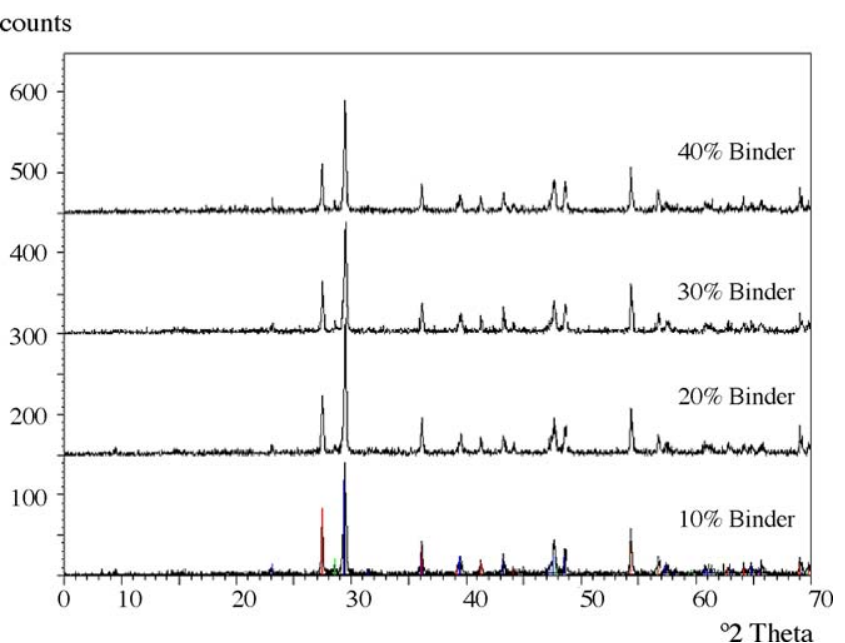

Fig. 10. X-ray diffraction diagram of the paint films.

\subsection{Permeability of the paint films}

To determine the effect of binder content on the barrier property of the paint films, water vapor permeation experiments were conducted. The permeabilities were estimated from Eq. (10) using experimentally collected relative humidity curves as a function of time and they are listed in Table 4. The drastic decrease in permeabilities with the increased binder content of the films is shown in Fig. 11. This behavior is explained by the formation of porous structure as the binder content decreases from $40 \%$ to $10 \%$. Not only the pore formation but also the nonhomogeneous distribution of the paint ingredients such as pigments and fillers in the cases of $20 \%$ and $10 \%$ binder contributes to a decline in barrier property of the paint films against water vapor. Similar results were reported by other groups. Bierwegan [22] discussed a strong relationship between the degree of dispersion of the pigment and durability of the coating. Brown et al. [23] indicated that uneven distribution and clustering of pigment crystals cause an increase in water vapor permeability of the emulsion paints. In addition, the size, shape and the geometry of the pigment were found to have a marked influence on

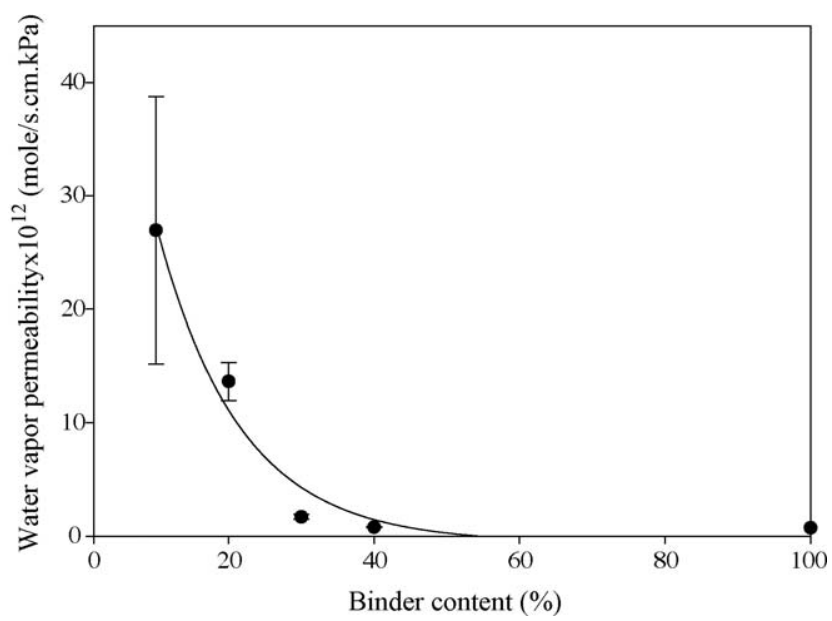

Fig. 11. Water vapor permeability of the films as a function of the binder content. the barrier properties of the paints [24]. Due to complex multicomponent mixture and the distribution of the ingredients in the paint films, it is difficult to compare permeabilities measured by different groups. Besides this fact, our experimental measurement for the permeability coefficient of the paint film formulated with $10 \%$ binder is in agreement with the value reported by Hulden and Hansen [24]. They have reported the permeability coefficient of water in pigmented acrylic latex coating as $28.3 \times 10^{-12} \mathrm{~mole} / \mathrm{s} \mathrm{cm} \mathrm{kPa}$. The reproducibility of the data is perfect in the cases of $30 \%, 40 \%$ binders and the pure binder as well. The largest deviation among the measurements is obtained for the films formulated with $10 \%$ binder content. This is mainly caused by nonhomogenous structure of these films due to uneven distribution of the pigments and fillers.

Most common inorganic pigments and fillers are impermeable, thus, moisture transport mainly takes place in the binder material. To gain an insight about the barrier property of the pure binder material, we have also measured its permeability coefficient. The value was found to be very close to that of the paint film formulated with $40 \%$ binder since this paint film has a relatively homogeneous and nonporous structure, similar to the structure of the pure copolymer film.

\section{Conclusion}

In this study, we have identified the unknown ingredients of the waterborne acrylic based paints applied as indoor and outdoor wall paints and observed the structure of the films using different modern characterization tools. In addition, we have measured their barrier properties in terms of water vapor permeabilities. The paints contained around $35 \%$ of water. Most common elements in all paint film samples were determined as carbon, oxygen, calcium, titanium, silicon, magnesium, aluminum and sodium. X-ray diffraction analysis has shown that titanum and calcium elements are present in the form of titania and calcite, respectively. Thermal gravimetric analysis indicated that pure binder material degrades at one step without leaving a thermally stable char at the end of $800{ }^{\circ} \mathrm{C}$, while paint films decompose at two steps, leaving a thermally stable char, which contains $\mathrm{CaO}$ and titania. We have found a good correlation between the enthalpy of the thermal degradation process and the binder content in the films. Our results suggest that DSC can be used to estimate the binder concentration in the paint films by determining the heat output from thermal decomposition of the organic fraction in the paint. DSC analysis has also indicated that glass transition temperature of the pure binder is slightly lower than those of the paint films. Characterization studies based on the scanning electron microscope pictures have shown that the structure of the paint films changes from dense to porous one with decreased binder content from $40 \%$ to $10 \%$. Furthermore, lower binder content leads to a higher pigment concentration in the film, consequently, a nonhomogeneous distribution of the pigment. As a matter of fact, porous structure formation is a result of the pigment flocculation due to insufficient wetting of the pigments by the binder. Another consequence of the nonhomogeneous dispersion of the pigments is the increase in water vapor permeability of the paint 
films. We have found that permeability coefficient of water vapor significantly increases as the binder content of the films decreases. The results indicate that the paint sample formulated with $40 \%$ binder content shows the best barrier property against water vapor. The water vapor permeability of this sample was found to be very close to that of the pure binder material.

Based on the characterization and permeation studies, it can be finally concluded that binder fraction in the waterborne paint is an important parameter since it directly influences the homogeneous or uneven distribution and flocculation of the pigment, pore formation in the final structure, consequently, the water transport and barrier property of these paints.

\section{Acknowledgments}

The authors would like to thanks TÜBİTAK (National Science Foundation of TURKEY) and İzmir Institute of Technology (IZTECH) for the financial support through Grants MISAG 144 and 1999 MÜH 04/2001 MÜH 16. We also gratefully acknowledge Organik Kimya A.S. and Akril Kimya A.S. for providing the pure binder material and paint samples and Material Research Center of IZTECH for SEM, XRD and EDX analyses.

\section{References}

[1] P. Thometzek, A. Ludwig, A. Karbach, K. Köhler, Prog. Org. Coat. 36 (1999) 201.

[2] E. Almeida, D. Santos, J. Uruchurtu, Prog. Org. Coat. 37 (1999) 131.
[3] E. Reuter, D.S. Silber, D.C. Psiorz, Prog. Org. Coat. 37 (1999) 161.

[4] C. Le Pen, C. Lacabanne, N. Pebere, Prog. Org. Coat. 39 (2000) 167.

[5] V. Guillaumin, D. Landolt, Corros. Sci. 44 (2002) 179.

[6] F. Galliano, D. Landolt, Prog. Org. Coat. 44 (2002) 217.

[7] B.d. Amo, L. Veleva, A.R. Di Sarli, C.I. Elsner, Prog. Org. Coat. 50 (2004) 179.

[8] M. Delucchi, A. Barbucci, G. Cerisola, Prog. Org. Coat. 33 (1998) 76.

[9] C. Perez, a. Collazo, M. Izquierdo, P. Merino, X.R. Novoa, Prog. Org. Coat. 36 (1999) 102.

[10] C. Perez, a. Collazo, M. Izquierdo, P. Merino, X.R. Novoa, Prog. Org. Coat. 37 (1999) 169.

[11] E.L.J. Goossens, A.J.J. van der Zanden, H.L.M. Wijen, W.H. van der Spoel, Prog. Org. Coat. 48 (2003) 112.

[12] E.L.J. Goossens, A.J.J. van der Zanden, W.H. van der Spoel, Prog. Org. Coat. 49 (2004) 270.

[13] E. Carretti, L. Dei, Prog. Org. Coat. 49 (2004) 282.

[14] F.B. Reigh, G.J.V. Adelantado, M.M.C.M. Moreno, Talanta 58 (2002) 811.

[15] İ. Sönmez, Y. Cebeci, Colloids Surf., A 225 (2003) 111.

[16] N.B. Colthup, L.H. Daly, S.E. Wiberley, Introduction to Infrared and Raman Spectroscopy, 3rd ed., Academic Press, Inc., California, 1990.

[17] R.I. Vitala, M. Langlet, J. Simola, M. Lindén, J.B. Rosenholm, Thin Solid Films 368 (2000) 35.

[18] M. Burgos, M. Langlet, Thin Solid Films 349 (1999) 19.

[19] D.Y. Perera, Prog. Org. Coat. 50 (2004) 247.

[20] C. Pagella, D.M. De Faveri, Prog. Org. Coat. 33 (1998) 211.

[21] K. Jeoung-Ah, J. Eur. Ceram. Soc. 24 (2004) 3823.

[22] G.P. Bierwagen, Prog. Org. Coat. 15 (1987) 179.

[23] R.G.F. Brown, C. Carr, M.E. Taylor, Prog. Org. Coat. 30 (1997) 185.

[24] M. Huldén, C.M. Hansen, Prog. Org. Coat. 13 (1985) 171. 